\title{
Prevalence of and Risk Factors for Hip Resurfacing Revision
}

\author{
A Cohort Study Into the Second Decade After the Operation
}

\author{
Gulraj S. Matharu, BSc(Hons), MRCS, MRes, Andrew Judge, BSc, MSc, PhD, David W. Murray, MD, FRCS(Orth), \\ and Hemant G. Pandit, FRCS(Tr \& Orth), DPhil \\ Investigation performed at the Nuffield Department of Orthopaedics, Rheumatology and Musculoskeletal Sciences, \\ Nuffield Orthopaedic Centre, University of Oxford, Oxford, United Kingdom
}

\begin{abstract}
Background: Most metal-on-metal hip resurfacing (MoMHR) designs have experienced high short-term failure rates because of pseudotumors. The impact of this complication into the second decade after the procedure is unknown. We investigated (1) the prevalence of, and risk factors for, all-cause and pseudotumor-related revision at up to 15 years following MoMHR and (2) whether risk factors were sex-specific.
\end{abstract}

Methods: This single-center prospective cohort study included 1,429 MoMHRs (1216 patients; 40\% female) implanted between 1999 and 2009. Patients were contacted in 2010 and 2012 as per national recommendations. Patients with symptoms related to the hip and/or suboptimal Oxford Hip Scores ( $\leq 41$ of 48 points) underwent cross-sectional imaging and blood metal-ion sampling. Revision diagnoses were established using operative and histopathological findings. Multivariate Cox proportional hazard models were used to assess the association of predictor variables with the time to all-cause and pseudotumor-related revisions.

Results: One hundred and eighty MoMHRs (12.6\%) were revised for all causes, and 111 ( $7.8 \%$ of the series and $61.7 \%$ of all revisions) were revised because of pseudotumor. Survival analysis showed the 15-year cumulative revision rate for all causes to be $19.5 \%$ (95\% confidence interval $[\mathrm{Cl}]=16.2 \%$ to $23.2 \%$ ) and the 15 -year rate of revision due to pseudotumor to be $14.0 \%(95 \% \mathrm{Cl}=11.0 \%$ to $17.7 \%$ ). Small femoral head size (hazard ratio $[\mathrm{HR}]$ per $2 \mathrm{~mm}=0.92,95 \% \mathrm{Cl}=0.88$ to 0.97 ; $p=0.003)$ and certain implant designs (HR $=1.55$ to $3.01 ; p \leq 0.029)$ significantly increased the all-cause revision risk. Female sex $(\mathrm{HR}=2.03,95 \% \mathrm{Cl}=1.19$ to $3.44 ; \mathrm{p}=0.009)$ and young age $(\mathrm{HR}$ per year $=0.98,95 \% \mathrm{Cl}=0.96$ to $1.00 ; \mathrm{p}=$ 0.020 ) significantly increased the pseudotumor-related revision risk but not the all-cause revision risk. Risk factors for allcause and pseudotumor-related revision were sex-specific. In females, small femoral head size $(p=0.014)$ increased the allcause revision risk, and young age was the only predictor of pseudotumor-related revision $(p=0.019)$. In males, implant design was the only predictor of all-cause revision $(p \leq 0.015)$ and pseudotumor-related revision $(p=0.001)$.

Conclusions: The prevalence and rates of revision for all causes and pseudotumor were high at up to 15 years following MoMHR. Predictors of revision differed between all-cause and pseudotumor-related revisions and were sex-specific. These factors must be appropriately weighted when risk-stratifying patients with MoMHRs for surveillance.

Level of Evidence: Prognostic Level II. See Instructions for Authors for a complete description of levels of evidence.

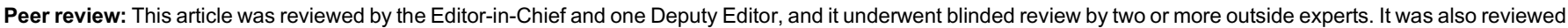

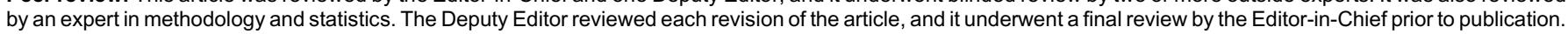
Final corrections and clarifications occurred during one or more exchanges between the author(s) and copyeditors.

$\mathrm{H}$ igh short-term failure rates $(9.7 \%$ to $12.6 \%$ at 10 years) have been reported for most metal-on-metal hip resurfacing (MoMHR) designs ${ }^{1,2}$. Revisions have

commonly been due to pseudotumors ${ }^{3,4}$, with the prevalence of this complication increasing annually'. Pseudotumor-related revision rates of $4 \%$ at 8 years have been reported ${ }^{5}$, with rates

Disclosure: Arthritis Research U.K. provided one of the authors with funding in the form of a Clinical Research Fellowship. On the Disclosure of Potential Conflicts of Interest forms, which are provided with the online version of the article, one or more of the authors checked "yes" to indicate that the author had a relevant financial relationship in the biomedical arena outside the submitted work. 


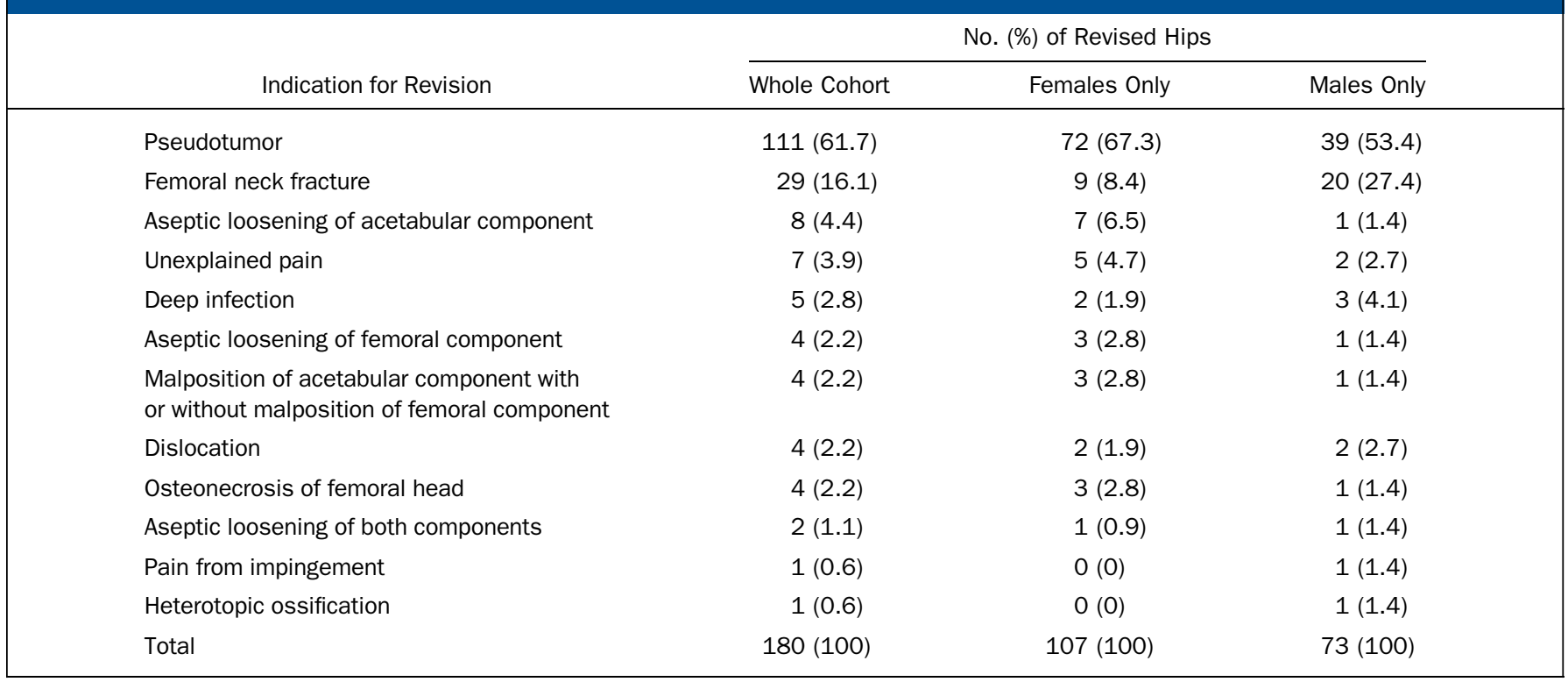

up to $25 \%$ at 6 years for implants withdrawn from the market ${ }^{6}$. Regular surveillance is therefore recommended for patients with MoMHR implants ${ }^{7-9}$.

Risk factors for all-cause MoMHR revision include female sex, small femoral components, implant design, and hip diagnoses other than primary osteoarthritis ${ }^{10-13}$. Pseudotumor risk factors are similar ${ }^{4,5}$ but also include malposition of the acetabular component ${ }^{14,15}$. Sex and femoral component size have complex interactions. Smaller components are more common in females as a result of anatomical differences, with females more frequently having abnormal acetabular anatomy compromising component placement, ${ }^{5,11}$ as well as metal allergies, which have been implicated in pseudotumor formation ${ }^{3,16}$. Authors of large MoMHR cohort studies have reported mixed conclusions regarding sex and femoral head size; some have suggested that female sex is the most important risk factor for failure ${ }^{10,17}$, while others have suggested that small components ${ }^{11,18}$ or a combination of both factors are the most important ${ }^{12}$. Regulatory authorities recently recommended against future implantation of the Birmingham Hip Resurfacing (BHR) prosthesis in all female patients and in males requiring small components $(\leq 48 \mathrm{~mm})$, with regular follow-up advised for these subgroups ${ }^{19}$.

Although studies assessing the prevalence of, and risk factors for, MoMHR revision have involved large cohorts, they have been limited by short-term follow-up (mean, 3.4 to 7.1 years $)^{5,10-12,17,18}$, with only one study specifically reporting pseudotumor prevalence and risk factors ${ }^{5}$, to our knowledge. The prevalence of all-cause and pseudotumor-related revision into the second decade following MoMHR arthroplasty is unknown, and given previous study limitations the reported risk factors for revision may be inaccurate. Knowledge of the correct revision predictors is important to inform follow-up regimens ${ }^{20}$, given that $>1$ million MoM hip prostheses have been implanted and require surveillance.
Registry studies potentially underestimate MoMHR revisions by up to $39 \%$, with outcomes frequently coded incorrectly $^{21}$. Furthermore, registries introduced pseudotumor as a revision indication only in 2009, without recording histopathological results ${ }^{1}$. Therefore, large cohort studies with detailed data and revision indications determined with histopathological analysis are the best way to assess the prevalence of all-cause and pseudotumor-related revisions.

We investigated (1) the prevalence of, and risk factors for, all-cause and pseudotumor-related revisions at up to 15 years following MoMHR, and (2) whether risk factors were sex-specific.

\section{Materials and Methods}

This single-center prospective cohort study included patients treated with 1 primary MoMHR between June 1999 and December 2009. Only patients with a minimum of 1 year of follow-up were included. There were 1,429 MoMHRs (1,216 patients) eligible for inclusion. Seven surgeons who had no role in the design of the implants performed all operations using four designs: BHR (Smith \& Nephew), Conserve Plus (Wright Medical Technology), ReCap (Biomet), and Cormet (Corin).

All patients were contacted in 2010 and 2012 because of alerts from the Medical and Healthcare products Regulatory Agency (MHRA) ${ }^{7,22}$. This contact involved a postal questionnaire inquiring about hip problems (pain, swelling, noises) and asking for completion of the Oxford Hip Score questionnaire (OHS; $0=$ worst outcome and $48=$ best outcome $)^{23,24}$. Patients with hip symptoms and/or a suboptimal OHS ( $\leq 41$ of 48 points) ${ }^{25}$ were evaluated as per MHRA recommendations ${ }^{7}$, using cross-sectional imaging ${ }^{26}$ and testing of blood metal-ion levels.

Data extracted from our prospectively maintained database included demographics (sex and age), primary hip diagnosis, and details regarding the MoMHR (design, component size, and whether the patient had bilateral implantation). The database and hospital records were reviewed for all patients to determine whether the MoMHR had been revised (including date, indication, surgical findings, and components removed/implanted). Revision surgery was defined as removal or exchange of any MoMHR component. The diagnoses 

Pseudotumor-Related Revision

\begin{tabular}{|c|c|c|c|c|c|c|c|}
\hline & $\begin{array}{l}\text { Whole Cohort } \\
(N=1,429)\end{array}$ & $\begin{array}{l}\text { No Revision } \\
(\mathrm{N}=1,249)\end{array}$ & $\begin{array}{l}\text { Revision for } \\
\text { Any Indication } \\
\quad(N=180)\end{array}$ & $P$ Value & $\begin{array}{c}\text { No } \\
\text { Pseudotumor- } \\
\text { Related } \\
\text { Revision } \\
(\mathrm{N}=1,318)\end{array}$ & $\begin{array}{l}\text { Pseudotumor- } \\
\text { Related } \\
\text { Revision } \\
(\mathrm{N}=111)\end{array}$ & P Value \\
\hline Sex (no. [\%]) & & & & $<0.001 *$ & & & $<0.001 *$ \\
\hline Male & $853(59.7)$ & $780(62.4)$ & $73(40.6)$ & & $814(61.8)$ & 39 (35.1) & \\
\hline Female & $576(40.3)$ & $469(37.6)$ & $107(59.4)$ & & $504(38.2)$ & $72(64.9)$ & \\
\hline $\begin{array}{l}\text { Mean age } \\
\text { (range) (yr) }\end{array}$ & $53.8(16.5-85.5)$ & $53.9(16.5-85.5)$ & $52.6(19.5-71.8)$ & 0.111 & $54.0(16.5-85.5)$ & $51.5(28.7-69.9)$ & $0.011 *$ \\
\hline $\begin{array}{l}\text { Laterality } \\
\text { (no. [\%]) }\end{array}$ & & & & 0.246 & & & 0.814 \\
\hline Unilateral & $1,003(70.2)$ & $870(69.7)$ & $133(73.9)$ & & $924(70.1)$ & $79(71.2)$ & \\
\hline Bilateral & $426(29.8)$ & 379 (30.3) & 47 (26.1) & & $394(29.9)$ & $32(28.8)$ & \\
\hline $\begin{array}{l}\text { Hip diagnosis } \\
\text { (no. [\%]) }\end{array}$ & & & & 0.880 & & & 0.439 \\
\hline $\begin{array}{l}\text { Primary } \\
\text { osteoarthritis }\end{array}$ & $1,253(87.7)$ & 1,096 (87.8) & $157(87.2)$ & & 1,155 (87.6) & $98(88.3)$ & \\
\hline Dysplasia & $122(8.5)$ & $107(8.6)$ & $15(8.3)$ & & $115(8.7)$ & $7(6.3)$ & \\
\hline Other & $54(3.8)$ & $46(3.7)$ & $8(4.4)$ & & $48(3.6)$ & $6(5.4)$ & \\
\hline $\begin{array}{l}\text { Mean femoral } \\
\text { head size } \\
\text { (range) }(\mathrm{mm})\end{array}$ & $48.4(38-58)$ & $48.7(38-58)$ & $46.8(38-54)$ & $<0.0001 *$ & $48.6(38-58)$ & $46.6(38-54)$ & $<0.0001^{*}$ \\
\hline Implant (no. [\%]) & & & & 0.098 & & & 0.481 \\
\hline $\begin{array}{l}\text { Birmingham } \\
\text { Hip Resurfacing }\end{array}$ & 641 (44.9) & $563(45.1)$ & $78(43.3)$ & & 591 (44.8) & $50(45.0)$ & \\
\hline Conserve & $631(44.2)$ & $551(44.1)$ & $80(44.4)$ & & $584(44.3)$ & $47(42.3)$ & \\
\hline ReCap & $139(9.7)$ & $123(9.8)$ & $16(8.9)$ & & $128(9.7)$ & $11(9.9)$ & \\
\hline Cormet & $18(1.3)$ & $12(0.96)$ & $6(3.3)$ & & $15(1.1)$ & $3(2.7)$ & \\
\hline
\end{tabular}

leading to the revision were determined using results of preoperative investigations and operative records. A revision was considered to be due to a pseudotumor if the operative and histological findings confirmed this ${ }^{26}$. If a revision had been performed elsewhere, the institution was contacted to obtain data. Revisions were identified as having occurred elsewhere when the patient informed us by telephone or mail, the patient provided revision details while being seen for other reasons, or the primary surgeon identified a revision in their registry profile ${ }^{1}$.

For the assessment of implant survival, patients were censored on the date of revision surgery or, if the MoMHR was not revised, on the date of their most recent clinical examination or questionnaire completion. The last potential follow-up date for this study was August 24, 2015. No patient who had undergone MoMHR was awaiting revision at the time of writing.

\section{Statistical Analysis}

The outcomes of interest were the time from the MoMHR to revision (1) for any indication and (2) due to pseudotumor. Predictive factors considered were age at the time of MoMHR surgery, sex, unilateral or bilateral MoMHR, primary diagnosis (primary osteoarthritis, dysplasia, or other), MoMHR design, and femoral component size. Differences in these covariates between the revision and non-revision groups were assessed using unpaired t tests for numerical data and either the chi-squared test with Yates' correction or Fisher's exact test for categorical data.

Survival analysis was performed using the Kaplan-Meier method. Cox proportional hazards models (univariate and multivariate) were used to assess the association of the predictor variables with the time to revision for each survival end point. For continuous predictors, fractional polynomial regression modeling was used to assess the assumption of linearity with outcome, with data categorized if the assumption was not satisfied. Likelihood ratio tests were used to assess evidence of 2-way interactions between sex and other predictors. Because of colinearity of sex and femoral component size, all subsequent analyses were stratified by sex. The significance level was $p<0.05$, with $95 \%$ confidence intervals (CIs) also used.

\section{Results}

ne hundred and eighty MoMHRs (in 156 patients) were revised for all causes at a mean of 4.8 years (range, 0.01 to 15.5 years) after the arthroplasty (Table I). The remaining 1,249 MoMHR implants (in 1,060 patients) remained in situ at the time of the latest follow-up, at a mean of 8.4 years (range, 1.0 to 15.4 years); the median OHS was 46 points (interquartile range, 42 to 48 points) at this time. A follow-up questionnaire was available for $94.9 \%(1,185)$ of the surviving hips (see Appendix).

\section{All-Cause Revision}

\section{Prevalence and Risk Factors}

The prevalence of all-cause revision was $12.6 \%$ (180 of 1,429$)$. Risk factors for all-cause revision, which are summarized in Table II, were sex-specific. 
The Journal of Bone \& Joint SURGERy $\cdot$ JBJS.ORG Volume 98-A · Number $17 \cdot$ September 7, 2016

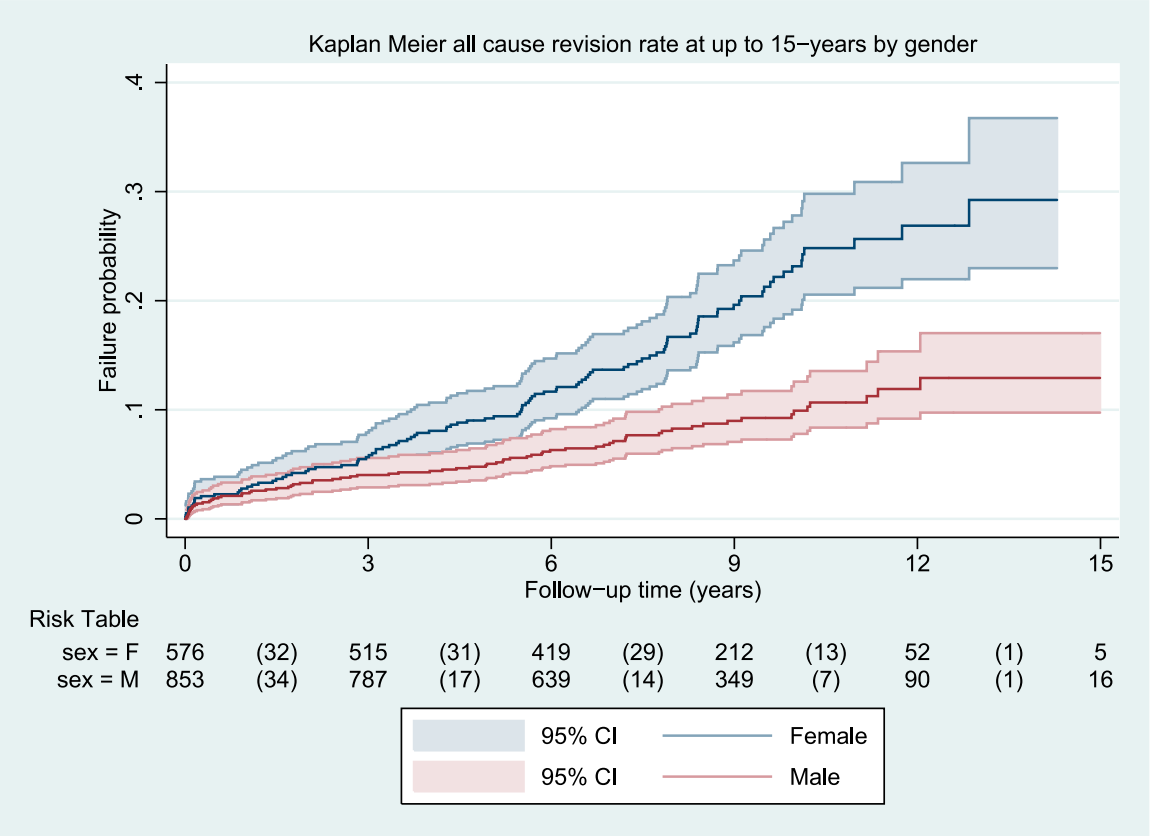

Fig. 1

Results of Kaplan-Meier survival analysis of the all-cause MoMHR revision rate up to 15 years for each sex. The shaded areas represent the respective upper and lower limits of the $95 \%$ Cls. The risk table indicates the number of hips at risk at 3-year intervals, with the number of hips revised during the 3-year interval in parentheses. The all-cause revision rate at 13 years was $29.2 \%$ (95\% $\mathrm{Cl}=23.0 \%$ to $36.7 \%$; 27 hips at risk) in females compared with $12.9 \%(95 \% \mathrm{Cl}=9.7 \%$ to 17.0\%; 57 hips at risk) in males. A univariate Cox proportional hazards model demonstrated that female sex was a significant predictor of all-cause revision $(\mathrm{HR}=2.25,95 \% \mathrm{Cl}=1.67$ to 3.04 ; $\mathrm{p}<0.001)$.

\section{Survival Analysis}

The all-cause MoMHR cumulative revision rate was $19.5 \%$ $(95 \% \mathrm{CI}=16.2 \%$ to $23.2 \%)$ at 15 years. Factors associated with a significantly increased revision risk in the univariate analyses

were female sex (Fig. 1), small femoral head size, and implant design. Multivariate Cox models (Table III) demonstrated that small femoral head size $(p=0.003)$ and non-BHR implants $(\mathrm{p} \leq 0.029)$ significantly increased revision risk; however, the

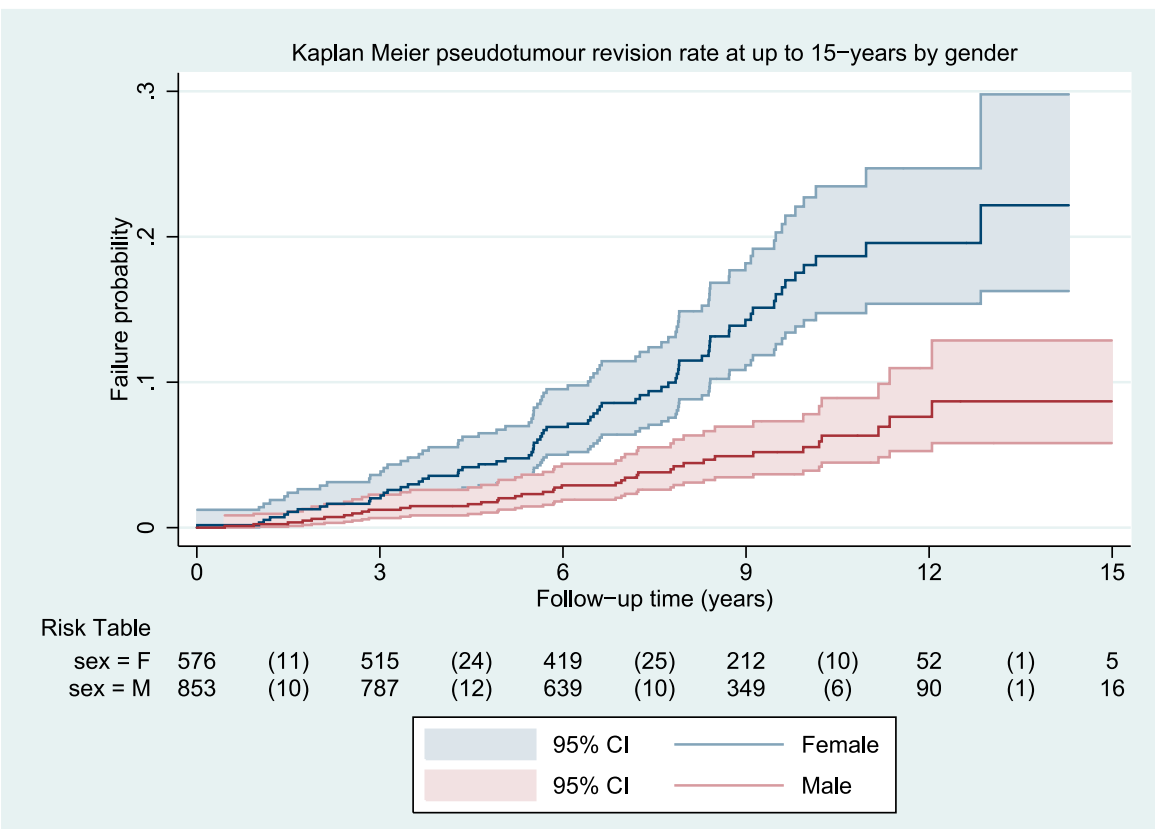

Fig. 2

Results of Kaplan-Meier survival analysis of the pseudotumor-related MoMHR revision rate up to 15 years for each sex. The shaded areas represent the respective upper and lower limits of the $95 \% \mathrm{Cls}$. The risk table indicates the number of hips at risk at 3-year intervals, with the number of hips revised during the 3-year interval in parentheses. The pseudotumor-related revision rate at 13 years was $22.2 \%(95 \% \mathrm{Cl}=16.3 \%$ to $29.8 \% ; 27$ hips at risk) in females compared with $8.7 \%(95 \% \mathrm{Cl}=5.8 \%$ to $12.9 \% ; 57$ hips at risk) in males. A univariate Cox proportional hazards model demonstrated that female sex was a significant predictor of pseudotumor-related revision $(\mathrm{HR}=2.86,95 \% \mathrm{Cl}=1.93$ to 4.22 ; $p<0.001)$. 


\begin{tabular}{|c|c|c|c|c|c|c|}
\hline \multirow[b]{3}{*}{ Covariate } & \multicolumn{6}{|c|}{ Revision for Any Indication } \\
\hline & \multicolumn{2}{|c|}{ Whole Cohort } & \multicolumn{2}{|c|}{ Females Only } & \multicolumn{2}{|c|}{ Males Only } \\
\hline & HR (95\% Cl) & P Value & HR (95\% Cl) & P Value & $\mathrm{HR}(95 \% \mathrm{Cl})$ & P Value \\
\hline Female vs. male & $1.48(0.98-2.22)$ & 0.062 & NA & NA & NA & NA \\
\hline Age (per year) & $0.99(0.98-1.01)$ & 0.252 & $0.98(0.96-1.00)$ & 0.062 & $1.01(0.98-1.03)$ & 0.594 \\
\hline Primary osteoarthritis & 1.00 & Baseline & 1.00 & Baseline & 1.00 & Baseline \\
\hline Dysplasia & $0.80(0.46-1.40)$ & 0.441 & $0.75(0.41-1.40)$ & 0.370 & $0.62(0.15-2.55)$ & 0.505 \\
\hline Other & $1.37(0.65-2.85)$ & 0.407 & $1.92(0.79-4.67)$ & 0.152 & $0.74(0.18-3.10)$ & 0.681 \\
\hline Femoral head size (per 2-mm) & $0.92(0.88-0.97)$ & $0.003 \dagger$ & $0.92(0.85-0.98)$ & $0.014 \dagger$ & $0.94(0.87-1.02)$ & 0.166 \\
\hline Cormet§ & 3.01 (1.30-6.95) & $0.010 \dagger$ & $3.49(1.36-8.94)$ & $0.009 \dagger$ & $1.88(0.25-14.11)$ & 0.539 \\
\hline
\end{tabular}

effect of female sex $(p=0.062)$ was no longer significant in the multivariate model for the whole cohort.

When the MoMHRs were divided by the sex of the patient (Table III), a multivariate Cox model analysis of the female group demonstrated that small femoral head size $(\mathrm{p}=$ $0.014)$ and implantation of a Cormet design $(\mathrm{p}=0.009)$ significantly increased revision risk. However, only 18 Cormet designs were implanted in this series. The multivariate model for the male group identified Conserve $(p=0.002)$ and ReCap $(\mathrm{p}=0.015)$ MoMHRs as the only factors significantly increasing revision risk.

\section{Pseudotumor-Related Revision}

Prevalence and Risk Factors

Of the 1,429 MoMHRs, $111(7.8 \%)$ in 95 patients were revised because of pseudotumor at a mean of 6.1 years (range, 0.5 to 15.5 years). Pseudotumor accounted for $61.7 \%$ of all revisions (Table I). Risk factors for pseudotumor-related revisions are summarized in Table II and were sex-specific.

\section{Survival Analysis}

The pseudotumor-related revision rate for all MoMHRs was $14.0 \%(95 \% \mathrm{CI}=11.0 \%$ to $17.7 \%)$ at 15 years. Univariate analyses demonstrated that factors significantly increasing the risk of pseudotumor-related revision were female sex $(\mathrm{p}<0.001$; Fig. 2), small femoral head size $(\mathrm{p}<0.001)$, young age at the time of the MoMHR $(\mathrm{p}=0.011)$, and Conserve $(\mathrm{p}=0.009)$ and ReCap ( $\mathrm{p}=0.007)$ implants. All factors remained significant in the multivariate model (Table III).
When the MoMHRs were divided by the patient's sex (Table III), a multivariate Cox model showed young age to be the only covariate significantly increasing pseudotumor-related revision risk in the female group $(\mathrm{p}=0.019)$. Small femoral head size was not significantly associated with pseudotumorrelated revision in females $(\mathrm{p}=0.189)$. The multivariate model identified Conserve $(\mathrm{p}=0.001)$ and $\operatorname{ReCap}(\mathrm{p}=0.001)$ implants as the only factors significantly increasing pseudotumorrelated revision risk in the male group.

\section{Discussion}

T e believe this to be the first independent study providing information on revision risk into the second decade following MoMHR. The prevalences of revision for all causes $(12.6 \%)$ and for pseudotumor $(7.8 \%)$ were high, with 15 -year revision rates of $19.5 \%$ and $14.0 \%$, respectively. The predictors of all-cause revisions (small femoral head size and non-BHR implants) differed from the predictors of pseudotumor-related revisions (female sex, small femoral head size, young age, and Conserve and ReCap implants). Furthermore, the predictors were sex-specific; implant design was the only predictor of all-cause and pseudotumorrelated revisions in males whereas, in females, small femoral head size was the only predictor of all-cause revisions and young age was the only factor predicting pseudotumor-related revision.

To our knowledge, 15-year outcomes have been reported in only one study, by a surgeon involved in the design of a commonly used hip resurfacing implant ${ }^{27}$. That study showed an overall revision rate of $4.2 \%$ following 1,000 BHRs. Our inferior rates are likely related to numerous factors, including patient 
Revision for Pseudotumor

\begin{tabular}{|c|c|c|c|c|c|}
\hline \multicolumn{2}{|c|}{ Whole Cohort } & \multicolumn{2}{|c|}{ Females Only } & \multicolumn{2}{|c|}{ Males Only } \\
\hline HR (95\% Cl) & P Value & HR $(95 \% \mathrm{Cl})$ & $P$ Value & HR (95\% Cl) & $P$ Value \\
\hline $2.03(1.19-3.44)$ & $0.009 \dagger$ & NA & NA & NA & NA \\
\hline $0.98(0.96-1.00)$ & $0.020 \dagger$ & $0.97(0.95-1.00)$ & $0.019 \dagger$ & $0.98(0.95-1.02)$ & 0.370 \\
\hline $1.05(0.69-1.61)$ & 0.813 & $1.24(0.74-2.09)$ & 0.410 & $0.81(0.38-1.73)$ & 0.581 \\
\hline 1.00 & Baseline & 1.00 & Baseline & 1.00 & Baseline \\
\hline $0.53(0.24-1.18)$ & 0.120 & $0.57(0.25-1.30)$ & 0.180 & キ & 1.00 \\
\hline $1.51(0.64-3.59)$ & 0.348 & $1.68(0.57-4.97)$ & 0.351 & $1.23(0.29-5.34)$ & 0.778 \\
\hline $0.94(0.88-1.00)$ & $0.045 \dagger$ & $0.95(0.87-1.03)$ & 0.189 & $0.94(0.84-1.04)$ & 0.235 \\
\hline 1.00 & Baseline & 1.00 & Baseline & 1.00 & Baseline \\
\hline $1.77(1.14-2.73)$ & $0.011 \dagger$ & $1.19(0.70-2.05)$ & 0.518 & $4.37(1.86-10.26)$ & $0.001 \dagger$ \\
\hline $2.79(1.40-5.55)$ & $0.003 \dagger$ & $1.89(0.72-4.94)$ & 0.196 & $6.54(2.14-19.97)$ & $0.001 \dagger$ \\
\hline $2.40(0.74-7.77)$ & 0.143 & $1.86(0.44-7.83)$ & 0.400 & $4.12(0.52-32.91)$ & 0.181 \\
\hline
\end{tabular}

selection, surgical experience, and implant design, with only $45 \%$ of our cohort having a BHR. Our 10-year all-cause revision rate of $15.3 \%(95 \% \mathrm{CI}=13.2 \%$ to $17.8 \%)$ is also higher than the $9.7 \%$ to $12.6 \%$ recorded in registries ${ }^{1,2}$, although registries may underreport revisions ${ }^{21}$.

Although pseudotumor was the most common indication for revision (62\% of all revisions), other large cohort studies with shorter follow-up have identified femoral neck fracture, component loosening, and osteonecrosis as primary modes of MoMHR failure ${ }^{10,11,17}$. The prevalence and rates of revision due to pseudotumor have increased substantially compared with the $1.8 \%$ prevalence and $4 \%$ rate of pseudotumor-related revision at 8 years noted in an early report ${ }^{5}$. Regular surveillance of MoMHRs from 2010 to 2012 and onward is an important contributory factor ${ }^{7-9,28}$; therefore, pseudotumor may become a more frequent revision indication compared with other modes of failure. However, registries may not accurately reflect pseudotumorrelated revision rates for some time, given that pseudotumor did not become a revision indication until $2009^{1}$ coupled with potential underreporting of MoMHR revision $s^{21}$.

Predictors of all-cause revision risk were small femoral head size ( $8 \%$ increased risk per 2 -mm decrease in head size) and non-BHR implants (1.6 to 3.0 times increased risk). Our findings support those from two large studies that also demonstrated small head size to be a more important predictor of allcause revision than female $\operatorname{sex}^{11,18}$. Small head size makes patients more prone to femoral component loosening and femoral neck fracture ${ }^{18}$. Furthermore, small components are sensitive to malposition, which can lead to edge loading, increased wear, and pseudotumor ${ }^{14,15}$. Our findings regarding implant design confirm those from joint registries ${ }^{1,2,10}$, designing surgeons ${ }^{27,29}$, and independent centers ${ }^{15,30,31}$, and support using the BHR in appropriately selected patients. Although others have reported hip dysplasia and osteonecrosis as risk factors for MoMHR failure $^{10,11,27}$, this was not observed in our study.

Predictors of all-cause revision were sex-specific. Small femoral head size was the most important predictor in females, and implant design was the only predictor in males. "Small" femoral head size differs between males $(\leq 48 \mathrm{~mm})$ and females $(\leq 42 \mathrm{~mm})$. Diametrically smaller components have lower tolerances for positioning error and are at increased risk of revi$\operatorname{sion}^{11,14,15,18}$. Therefore our data suggest that small head size is a significant predictor of revision in females regardless of implant design. However, there is a slightly greater margin for error when positioning small components in males, so males may have a good outcome with a small component if an established MoMHR design is used. Despite the BHR being the best-performing MoMHR device worldwide ${ }^{1,2,10}$, our data support recent recommendations to not implant small femoral heads in females ${ }^{19}$.

Pseudotumors have predominantly been reported in females ${ }^{3,4,10,17}$. Our study showed that pseudotumor-related revision was predicted by female sex ( 2 times increased revision risk) and young age ( $2 \%$ increase in revision risk per year younger). Our data suggest that, in contrast to all-cause revision, pseudotumorrelated revision is more strongly predicted by female sex than by small femoral head size. Females have an increased risk of pseudotumor for various reasons. First, they have larger native head-neck ratios, which can be considerably reduced following MoMHR, thereby increasing the risk of edge loading and high wear $^{32}$. Using smaller implants in females, who more frequently have abnormal acetabular anatomy ${ }^{10,11,27}$, increases the risk of malposition, which can also cause high wear ${ }^{14,15}$. Females also have an increased risk of metal allergy ${ }^{16}$, which may contribute to pseudotumors. Increased hip movement and flexibility as well as specific gait patterns in females ${ }^{33,34}$ may cause impingement and/or edge loading with subsequent pseudotumor formation. 
The Journal of Bone \& Joint Surgery · Jbjs.org Volume 98-A • Number $17 \cdot$ September 7, 2016
Prevalence of and Risk Factors for Hip Resurfacing Revision

be interpreted in combination with registry data ${ }^{1,2}$ before widespread introduction of new technologies. Adopting this approach will allow innovation to continue while ensuring patient safety.

The strengths of our study include the large sample size and longer follow-up compared with previous reports $s^{5,10-12,17,18}$. Systematic methods, including contacting other centers, were used to identify all revisions. All revision indications were retrospectively confirmed using operative and histopathological findings, allowing us to identify revisions that were due to pseudotumor before this diagnosis was established ${ }^{3,4}$. In contrast, registries ${ }^{1,2,11-13}$, which are substantially limited by a lack of histopathological data, did not recognize pseudotumors until 2009 and underreport revisions ${ }^{21}$. Another strength of our study is that we employed robust survival analysis methodology, including sex-specific analysis. Also, the generalizability of our findings was improved by the fact that procedures were performed at a non-designing center with numerous surgeons using a range of common implants.

A limitation of our study and subsequent cohorts is the potential for surveillance bias. Because surgeons were unaware of pseudotumors before $2007^{3}$, this complication was underreported. However, our retrospective review identified pseudotumors in patients who underwent revision for other indications prior to 2007. Pseudotumors were more likely to be recognized after 2007, with patient recalls in $2010^{22}$ and $2012^{7}$, which included asymptomatic individual $\mathrm{s}^{38,39}$. The increased awareness of pseudotumors and regular patient surveillance are likely to further inflate the reported pseudotumor prevalence and pendent authorities ${ }^{7,9}$. The results of this initial experience must

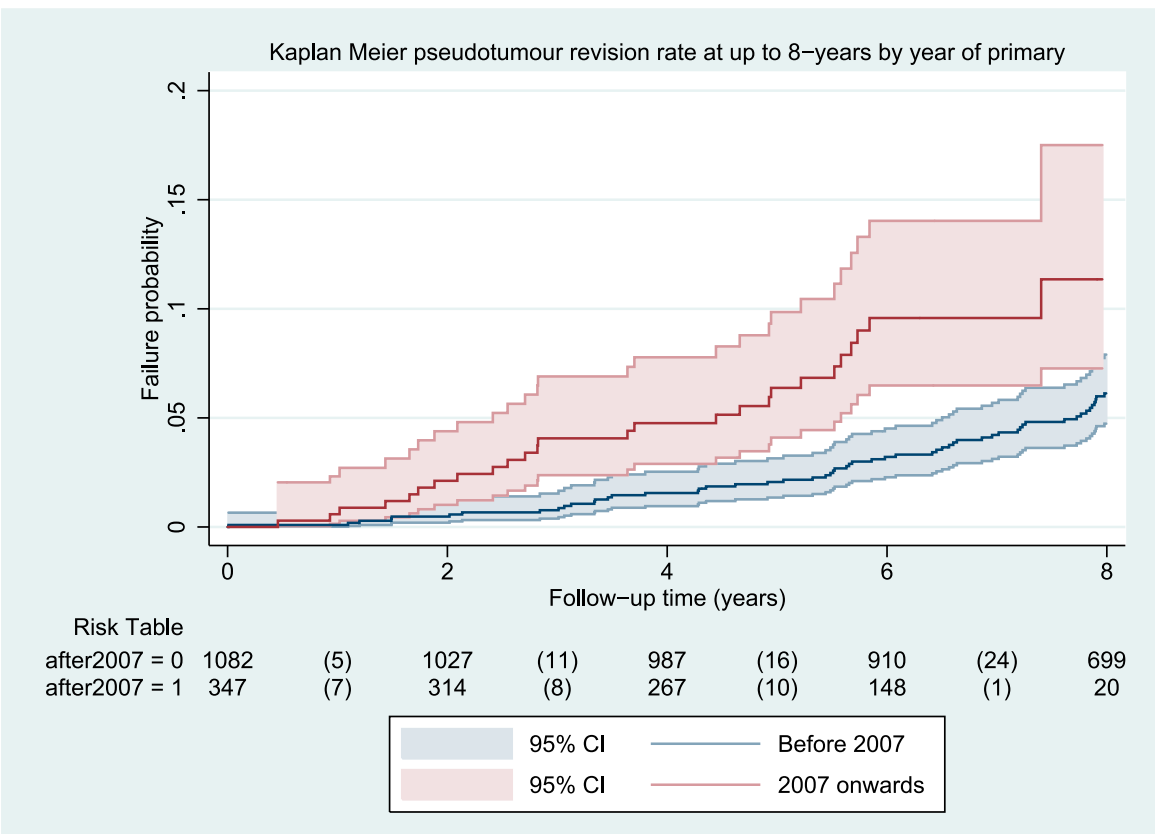

Fig. 3

Results of Kaplan-Meier survival analysis of the pseudotumor-related MoMHR revision rate up to 8 years according to whether the primary surgery

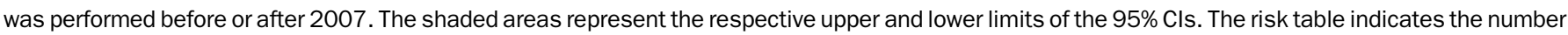
of hips at risk at 2-year intervals, with the number of hips revised during the 2-year interval in parentheses. A univariate Cox proportional hazards

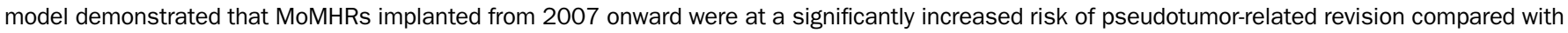
those implanted prior to $2007(\mathrm{HR}=2.44,95 \% \mathrm{Cl}=1.51$ to $3.95 ; \mathrm{p}<0.001)$. 
The Journal of Bone \& Joint Surgery $\cdot$ Jbjs.org Volume 98-A · Number $17 \cdot$ September 7, 2016
Prevalence of and Risk Factors for Hip Resurfacing Revision

to define failure as it represents a problem serious enough to warrant surgery. However, some patients who did not undergo revision may have had radiographic evidence of failure or asymptomatic pseudotumors ${ }^{39}$. These additional cases might eventually increase our reported prevalence and rates of revision, but the natural history of asymptomatic pseudotumors remains uncertain $^{46}$. It is not clear whether all such lesions eventually require revision ${ }^{46}$, as the frequency of asymptomatic pseudotumors is similar between patients with MoM implants and those with non-MoM implants ${ }^{47}$. An additional limitation is that, although our survival analysis was robust, there is a potential for residual confounding. Finally, our findings could have been influenced by some patients not completing the postal questionnaire and the possibility that some underwent revision abroad.

In conclusion, this study of a large cohort of MoMHRs showed a high prevalence and rate of all-cause and pseudotumorrelated revisions at up to 15 years following primary arthroplasty. Predictors of revision differed between all-cause and pseudotumor-related revisions, and were sex-specific. These factors must be appropriately weighted and incorporated into current worldwide follow-up recommendations ${ }^{7-9,28}$ for riskstratifying patients with MoMHRs for surveillance.

\section{Appendix}

eA A table showing patient and implant factors for surviving questionnaire versus those who did not complete the questionnaire is available with the online version of this article as a data supplement at jbjs.org.

Nоте: The authors thank the team involved in the patient recall, including the radiology department and the surgeons performing the primary and revision operations. $(50 \%)$ and rerevision $(38 \%)$ rates as well as inferior functional outcomes compared with those following primary THRs $\mathrm{s}^{40,41}$. Another concern is that the outcomes of revisions of metal-onpolyethylene THRs appear to be more favorable than those following pseudotumor-related revisions. The 10-year implant survival rate following revision of THRs due to late aseptic loosening was reported to be $84 \%$ in a large cohort, with patients with surviving implants having good functional outcomes ${ }^{42}$. Similar outcomes have been demonstrated in other studies following revision $\mathrm{THR}^{43,44}$. Given that many MoMHR implants may still require revision because of pseudotumor and the substantial difference between the outcomes following revisions of MoMHRs and those following revision of THRs, regular surveillance of patients with MoMHRs is important coupled with a low threshold for considering revision surgery. Indeed, there is already evidence that such a strategy may improve patient outcomes following MoMHR revision ${ }^{45}$.

Our study had other recognized limitations. The findings may not apply to other MoMHR designs. Also, revision was used
Gulraj S. Matharu, BSc(Hons), MRCS, MRes ${ }^{1}$

Andrew Judge, BSc, MSc, $\mathrm{PhD}^{1,2}$

David W. Murray, MD, FRCS(Orth) ${ }^{1}$

Hemant G. Pandit, FRCS(Tr \& Orth), DPhil ${ }^{1}$

${ }^{1}$ Nuffield Department of Orthopaedics, Rheumatology and Musculoskeletal Sciences, Nuffield Orthopaedic Centre, University of Oxford, Oxford, United Kingdom

${ }^{2}$ MRC Lifecourse Epidemiology Unit, Southampton General Hospital, University of Southampton, Southampton, United Kingdom

E-mail address for G.S. Matharu: gsm@doctors.org.uk

E-mail address for A. Judge: andrew.judge@ndorms.ox.ac.uk

E-mail address for D.W. Murray: david.murray@ndorms.ox.ac.uk

E-mail address for H.G. Pandit: hemant.pandit@ndorms.ox.ac.uk

\section{References}

1. National Joint Registry. 12th annual report 2015: National Joint Registry for England, Wales, Northern Ireland and the Isle of Man. http://www.njrcentre.org.uk/ njrcentre/Portals/0/Documents/England/Reports/12th\%20annual\%20report/ NJR\%200nline\%20Annual\%20Report\%202015.pdf. Accessed 2016 Feb 10. 2. Australian Orthopaedic Association National Joint Replacement Registry. Hip and knee arthroplasty: annual report 2015. https://aoanjrr.sahmri.com/
documents/10180/217745/Hip\%20and\%20Knee\%20Arthroplasty. Accessed 2016 Feb 10.

3. Pandit $\mathrm{H}$, Glyn-Jones $\mathrm{S}$, McLardy-Smith $\mathrm{P}$, Gundle R, Whitwell $\mathrm{D}$, Gibbons $\mathrm{CL}$, Ostlere S, Athanasou N, Gill HS, Murray DW. Pseudotumours associated with metal-on-metal hip resurfacings. J Bone Joint Surg Br. 2008 Jul;90(7): 847-51. 
The Journal of Bone \& Joint Surgery $\cdot$ Jbjs.org Volume 98-A • Number $17 \cdot$ September 7, 2016
Prevalence of and Risk Factors for Hip Resurfacing Revision

27. Daniel J, Pradhan $\mathrm{C}$, Ziaee $\mathrm{H}$, Pynsent PB, McMinn DJ. Results of Birmingham hip resurfacing at 12 to 15 years: a single-surgeon series. Bone Joint J. 2014 Oct; 96-B(10):1298-306.

28. Kwon YM, Lombardi AV, Jacobs JJ, Fehring TK, Lewis CG, Cabanela ME. Risk stratification algorithm for management of patients with metal-on-metal hip arthroplasty: consensus statement of the American Association of Hip and Knee Surgeons, the American Academy of Orthopaedic Surgeons, and the Hip Society. J Bone Joint Surg Am. 2014 Jan 1;96(1):e4.

29. Matharu GS, McBryde CW, Pynsent WB, Pynsent PB, Treacy RB. The outcome of the Birmingham Hip Resurfacing in patients aged $<50$ years up to 14 years postoperatively. Bone Joint J. 2013 Sep;95-B(9):1172-7.

30. Murray DW, Grammatopoulos G, Pandit H, Gundle R, Gill HS, McLardy-Smith P. The ten-year survival of the Birmingham hip resurfacing: an independent series. J Bone Joint Surg Br. 2012 Sep;94(9):1180-6.

31. Mehra A, Berryman F, Matharu GS, Pynsent PB, Isbister ES. Birmingham Hip Resurfacing: a single surgeon series reported at a minimum of 10 years follow-up. J Arthroplasty. 2015 Jul;30(7):1160-6. Epub 2015 Feb 2.

32. Grammatopoulos G, Pandit H, Murray DW, Gill HS; Oxford Hip and Knee Group. The relationship between head-neck ratio and pseudotumour formation in metal-onmetal resurfacing arthroplasty of the hip. J Bone Joint Surg Br. 2010 Nov;92(11): 1527-34.

33. Youdas JW, Krause DA, Hollman JH, Harmsen WS, Laskowski E. The influence of gender and age on hamstring muscle length in healthy adults. J Orthop Sports Phys Ther. 2005 Apr;35(4):246-52.

34. Murray DW, Grammatopoulos G, Gundle R, Gibbons CL, Whitwell D, Taylor A, Glyn-Jones S, Pandit HG, Ostlere S, Gill HS, Athanasou N, McLardy-Smith P. Hip resurfacing and pseudotumour. Hip Int. 2011 May-Jun;21(3):279-83. Epub 2011 Jun 9.

35. Whitehouse MR, Endo M, Zachara S, Nielsen TO, Greidanus NV, Masri BA, Garbuz DS, Duncan CP. Adverse local tissue reactions in metal-on-polyethylene total hip arthroplasty due to trunnion corrosion: the risk of misdiagnosis. Bone Joint J. 2015 Aug;97-B(8):1024-30.

36. Plummer DR, Berger RA, Paprosky WG, Sporer SM, Jacobs JJ, Della Valle CJ. Diagnosis and management of adverse local tissue reactions secondary to corrosion at the head-neck junction in patients with metal on polyethylene bearings. J Arthroplasty. 2016 Jan;31(1):264-8. Epub 2015 Aug 1.

37. Kwon YM, Fehring TK, Lombardi AV, Barnes CL, Cabanela ME, Jacobs JJ. Risk stratification algorithm for management of patients with dual modular taper total hip arthroplasty: consensus statement of the American Association of Hip and Knee Surgeons, the American Academy of Orthopaedic Surgeons and the Hip Society. J Arthroplasty. 2014 Nov;29(11):2060-4. Epub 2014 Jul 31.

38. Kwon YM, Ostlere SJ, McLardy-Smith P, Athanasou NA, Gill HS, Murray DW. "Asymptomatic" pseudotumors after metal-on-metal hip resurfacing arthroplasty: prevalence and metal ion study. J Arthroplasty. 2011 Jun;26(4):511-8. Epub 2010 Jun 29.

39. Low AK, Matharu GS, Ostlere SJ, Murray DW, Pandit HG. How should we followup asymptomatic metal-on-metal hip resurfacing patients? A prospective longitudinal cohort study. J Arthroplasty. 2016 Jan;31(1):146-51. Epub 2015 Aug 14.

40. Grammatopoulos G, Pandit H, Kwon YM, Gundle R, McLardy-Smith P, Beard DJ, Murray DW, Gill HS. Hip resurfacings revised for inflammatory pseudotumour have a poor outcome. J Bone Joint Surg Br. 2009 Aug;91(8):1019-24.

41. Matharu GS, Pynsent PB, Dunlop DJ. Revision of metal-on-metal hip replacements and resurfacings for adverse reaction to metal debris: a systematic review of outcomes. Hip Int. 2014 Jul-Aug;24(4):311-20. Epub 2014 May 23.

42. Philpott A, Weston-Simons JS, Grammatopoulos G, Bejon P, Gill HS, McLardySmith P, Gundle R, Murray DW, Pandit H. Predictive outcomes of revision total hip replacement-a consecutive series of 1176 patients with a minimum 10-year followup. Maturitas. 2014 Feb;77(2):185-90. Epub 2013 Nov 7.

43. Ornstein E, Linder L, Ranstam J, Lewold S, Eisler T, Torper M. Femoral impaction bone grafting with the Exeter stem - the Swedish experience: survivorship analysis of 1305 revisions performed between 1989 and 2002. J Bone Joint Surg Br. 2009 Apr;91(4):441-6.

44. Gilbody J, Taylor C, Bartlett GE, Whitehouse SL, Hubble MJ, Timperley AJ, Howell JR, Wilson MJ. Clinical and radiographic outcomes of acetabular impaction grafting without cage reinforcement for revision hip replacement: a minimum ten-year followup study. Bone Joint J. 2014 Feb;96-B(2):188-94.

45. De Smet KA, Van Der Straeten C, Van Orsouw M, Doubi R, Backers K, Grammatopoulos G. Revisions of metal-on-metal hip resurfacing: lessons learned and improved outcome. Orthop Clin North Am. 2011 Apr;42(2):259-69, ix.

46. van der Weegen W, Brakel K, Horn RJ, Hoekstra HJ, Sijbesma T, Pilot P, Nelissen RG. Asymptomatic pseudotumours after metal-on-metal hip resurfacing show little change within one year. Bone Joint J. 2013 Dec;95-B(12):1626-31.

47. Bisseling $P$, de Wit BW, Hol AM, van Gorp MJ, van Kampen $A$, van Susante JL. Similar incidence of periprosthetic fluid collections after ceramic-on-polyethylene total hip arthroplasties and metal-on-metal resurfacing arthroplasties: results of a screening metal artefact reduction sequence-MRI study. Bone Joint J. 2015 Sep;97-B(9):1175-82. 